ISSN: 2174-5609

DOI. https://doi.org/10.14198/INTURI2022.23.17

Cita bibliográfica: González Vázquez, D., Abulí Vergés, O.y Besolí Martín, A. (2022). Análisis estratégico de un recurso patrimonial territorial: Los refugios antiaéreos de la Guerra Civil española en la provincia de Girona (Cataluña). Investigaciones Turísticas (23), pp. 379-401. https://doi.org/10.14198/INTURI2022.23.17

\title{
Análisis estratégico de un recurso patrimonial territorial: los refugios antiaéreos de la Guerra Civil española en la provincia de Girona (Cataluña)
}

Strategic Tourism Analysis of a Territorial Heritage Resource: The Spanish Civil War Air-raid Shelters in the Province of Girona (Catalonia)

David González Vázquez (iD) Universidad de Barcelona, España

david.gonzalez@ub.edu

Oriol Abulí Vergés (iD) Universidad de Girona, España

oriol5abuli@gmail.com

Andrés Besolí Martín (iD, Universidad de Barcelona, España

abesoli@ub.edu

\section{RESUMEN}

El presente artículo tiene como objetivo el análisis estratégico turístico de los refugios antiaéreos de la Guerra Civil española (1936-1939), y su capacidad factual y potencial de turistización. El estudio se centra en el caso de la provincia catalana de Girona, territorio con unas especificidades históricas y geográficas que han propiciado una situación singular en la conservación de este valioso conjunto patrimonial cultural. La investigación incluye un estado de la cuestión sobre el problema y una aproximación metodológica de carácter cualitativo mediante la matriz de análisis DAFO, así como las técnicas de trabajo de campo y entrevista informal no estructurada a expertos en el tema y personal técnico de la administración local. El trabajo propugna que los refugios antiaéreos constituyen una categoría relevante, bien definida y estudiada dentro de los vestigios patrimoniales de la Guerra Civil, cuya valorización turística en la zona es aún escasa, pero con un enorme potencial de crecimiento. En este sentido, se valida la hipótesis de partida y se concluye que dicho crecimiento requiere de una gestión estratégica territorial integral, inexistente hasta la fecha, que involucre a todos los agentes turísticos y culturales implicados en la gestión y puesta en valor de este extenso conjunto patrimonial en la provincia de Girona.

Palabras clave: Turismo patrimonial; análisis estratégico; refugios antiaéreos; guerra civil española; Girona 


\section{ABSTRACT}

This paper seeks to conduct a tourism strategic analysis of the air-raid shelters of the Spanish Civil War (1936-1939), and their factual capacity and potential for attracting tourists. The study focuses on the case of the Catalan province of Girona, a territory with historical and geographical specificities that have provided a unique situation in the conservation of this significant cultural heritage site. The research includes a state of the question regarding the issue, taking a qualitative methodological approach, based on the SWOT analysis matrix, field work and also informal unstructured interviews with subject matter experts and technical staff of the local administration. The work advocates that air-raid shelters constitute a relevant, well-defined and studied category within the Spanish Civil War's heritage vestiges, the tourist value of which is still scarce in this area, but with an enormous growth potential. In this regard, the initial hypothesis is validated and we can conclude that such growth requires a comprehensive strategic management, non-existent to date, which involves all the tourist and cultural agents engaged in the management and enhancement of this extensive heritage landscape in the province of Girona.

Keywords: Heritage tourism; strategic analysis; air-raid shelters; spanish civil war; Girona

\section{INTRODUCCIÓN}

El turismo cultural representa en la actualidad un modelo de práctica turística bien consolidado alrededor del mundo. Las motivaciones de tipo cultural suponen una parte muy significativa del global de causas que estimulan al turista a visitar determinados destinos, de la misma forma que los organismos de gestión turística fomentan la puesta en valor de los bienes patrimoniales para la atracción de público interesado en ellos.

La permanente evolución del turismo cultural, con sus variadas formas de promoción y aprovechamiento, hace que cada vez sean más diversificados los tipos de patrimonio que despiertan el interés tanto de autóctonos como de visitantes foráneos (Timothy, 2011). Lejos ha quedado ya la primera definición de turismo cultural, que lo catalogaba como "aquella forma de turismo que tiene por objeto, entre otros fines, el conocimiento de monumentos y sitios histórico-artísticos" (ICOMOS, 1976). Desde entonces, las propuestas epistemológicas efectuadas en el marco de la teoría turístico-cultural han sido abundantes, destacando el hecho de que, además de la visita explícita a lugares patrimoniales, cobren también importancia la cultura popular y otras formas de patrimonio intangibles (Richards, 2002), así como la constatación de que la práctica del turismo cultural puede ser definida en gran parte por la actitud del turista y no sólo por el objeto de atracción (Donaire, 2012).

Más allá del tronco común que englobaría al turismo cultural, existe una gran variedad de tipologías turísticas que, relacionadas con patrimonios concretos, se han venido desarrollando y consolidando en los últimos años mediante la promoción de nuevos destinos y motivaciones más concretas. En este estudio hemos tomado en consideración el turismo de memoria (González Vázquez, 2017, 2018a; González y Mundet, 2018) como modelo de práctica turística aplicable al caso del conjunto patrimonial de los refugios antiaéreos de la Guerra Civil española en la provincia de Girona. Dichos elementos patrimoniales tienen una presencia relativamente importante en el territorio $y$, aunque la gran mayoría permanecen al margen de cualquier estrategia de valorización patrimonial o turística, un número significativo 
de refugios se ha abierto al público e incorporado a la agenda cultural de diferentes municipios gerundenses.

La recuperación y dignificación de los refugios antiaéreos debe ser enmarcada en el contexto global de la recuperación de la memoria histórica en España. Un "momento memoria" (Saz, 2007) al que se ha llegado tras cuarenta años de dictadura franquista que sobrevino al desenlace de la Guerra Civil, y después de cuatro décadas de democracia en las que la memoria de los vencidos se convirtió en una suerte de tabú en los ámbitos político y social (Silva, 2011). La apuesta por relacionar la recuperación de dicha memoria con una estrategia de carácter turístico ha sido claramente escenificada en Cataluña (González Vázquez, 2014, 2016) donde se ha implementado un plan de valorización de sus espacios de memoria con el fin de acercarlos al visitante, obteniendo a su vez un efecto reparador a nivel memorial (Guixé, 2008, 2009).

Es evidente que, más allá de los propios refugios de la Guerra Civil, existen otros elementos de interés, tanto cultural como natural, que podrían tener un papel relevante en la mejora de su capacidad de atracción. Sin embargo, su estudio se planteará en sucesivas fases de la investigación en las cuales se proyecte una ampliación de la muestra de expertos entrevistados a otros sectores del turismo de la zona. Así pues, en el presente artículo realizamos un estado de la cuestión del caso propuesto, un estudio de campo de los refugios antiaéreos visitables y un análisis estratégico de los factores, tanto de orden interno como externo, que condicionan la puesta en valor de los espacios integrados en la oferta turístico cultural vigente, así como de aquellos que permanecen inactivos, pero con un significativo potencial para su activación turística.

\section{HIPÓTESIS Y METODOLOGÍA}

La experiencia investigadora y profesional acumulada por los autores del presente trabajo en torno a los refugios de la Guerra Civil y su puesta en valor permite constatar que dicha tipología patrimonial suscita un gran interés social y turístico. En concreto, los espacios aquí analizados presentan un estado de conservación variado, pero en general óptimo para su correcta visita, ya sea de manera regular o puntual, con las medidas de adecuación oportunas. También se da la circunstancia de que en numerosos casos el enclave se encuentra ubicado en el centro histórico del municipio y resulta fácilmente accesible mediante transporte público o privado. De este modo, su puesta en valor (efectiva o potencial) no solo es plenamente compatible con políticas de socialización del conocimiento histórico, así como la difusión de valores como la paz y la convivencia democrática, sino también viable desde una perspectiva logística y de gestión turística cultural sostenible (Velasco, 2009).

En el otro lado de la balanza hay que señalar que, si bien tanto la legislación española como catalana han reconocido el valor histórico del legado material de la Guerra Civil como parte de la memoria colectiva, todavía no se ha establecido un plan estratégico estatal financiado para fomentar la conservación y difusión del mismo, y que posibilite su integración, con una gestión turística eficaz, dentro del modelo turístico-cultural vigente. A esto se suma el hecho de que muchos de los refugios antiaéreos que han llegado hasta nuestros días son infraestructuras subterráneas creadas para satisfacer las necesidades de protección inmediata de la población entre 1936 y 1939, y tras décadas de olvido por lo general no reúnen las medidas de seguridad, ventilación y evacuación protocolarias para convertirlos en espacios 
abiertos al público. Este hecho aconseja llevar a cabo un plan de rehabilitación previo a su musealización y puesta en valor en clave turística para garantizar tanto la conservación del bien patrimonial como la integridad de los visitantes (Figura 1).

Figura 1. Interior del Refugio del Puig de Sant Feliu, sito en Sant Feliu de Guíxols, uno de los espacios acondicionados para su activación turística analizados en este estudio

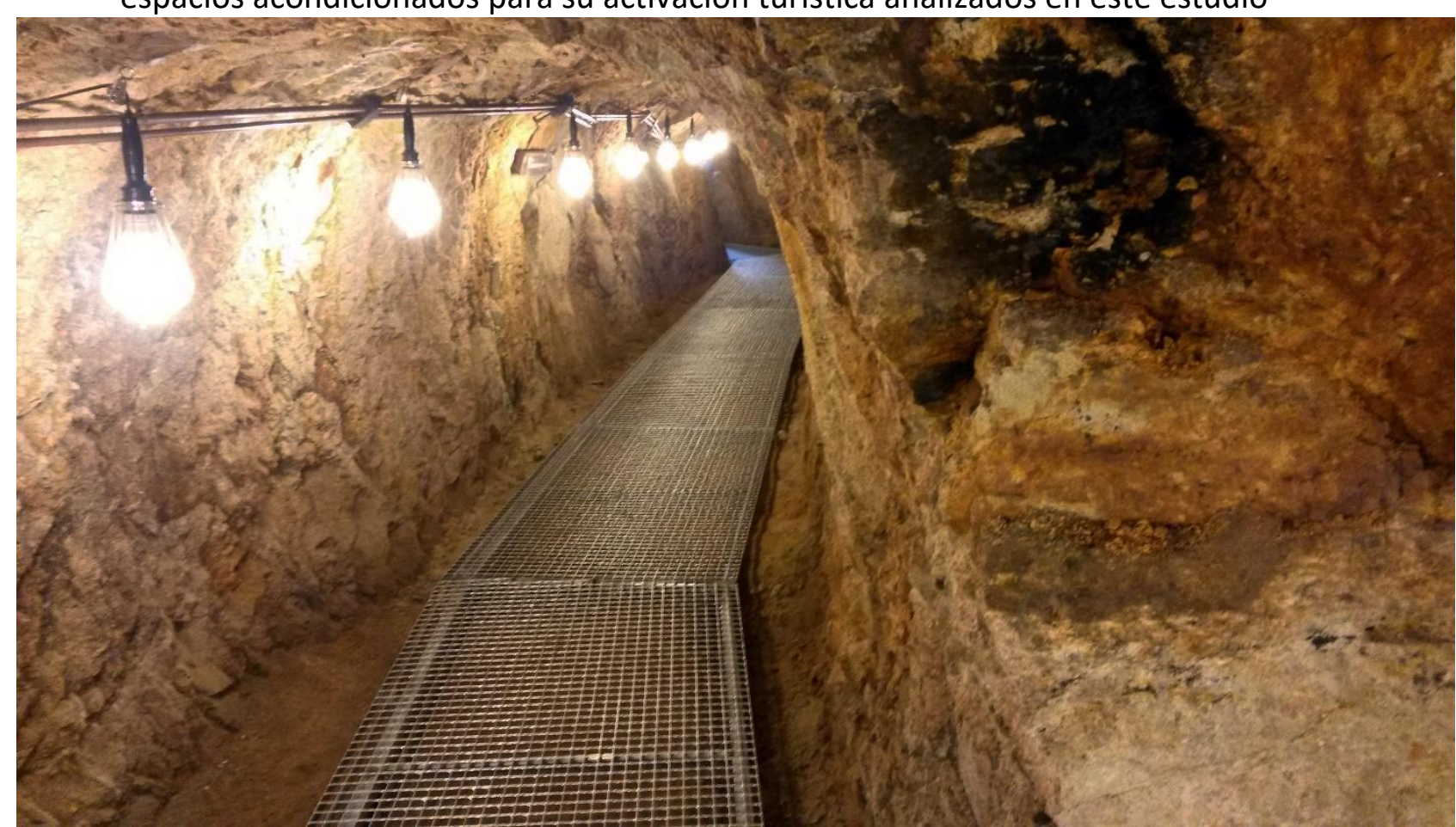

(Fotografía: Fons Ajuntament. Arxiu Municipal de Sant Feliu de Guíxols)

Una vez presentado brevemente el contexto turístico patrimonial relativo al estudio de caso, la hipótesis que se formula sostiene que el patrimonio inmueble de la Guerra Civil española, y específicamente el caso analizado de los refugios antiaéreos en la provincia de Girona, presenta un enorme potencial como recurso turístico, a semejanza de otros conjuntos análogos vinculados con las guerras y conflictos del siglo XX en diversos países europeos, aunque todavía constituye un activo infravalorado por la administración pública.

Con la finalidad de comprobar dicha hipótesis, se plantea un análisis estratégico basado en la metodología cualitativa vertebrado en dos fases. En la primera, se ha llevado a cabo una exhaustiva exploración bibliográfica de las fuentes primarias y secundarias existentes sobre el tema, así como treinta entrevistas informales no estructuradas, a través del teléfono y el correo electrónico, a expertos en el tema y a personal técnico y de gestión de ayuntamientos y organismos locales implicados. Esto ha permitido crear una base de datos de los 16 refugios antiaéreos visitables en 10 municipios gerundenses, de los 84 que perviven en la actualidad del total de 168 construidos durante la guerra en todo el territorio de la provincia, con información actualizada sobre su estado de conservación y gestión. Paralelamente, se diseñó una ficha como instrumento de observación de campo para identificar y clasificar una serie de características vinculadas a su activación turística. Dichas características se clasificaron en distintas categorías: las que definen la realidad de los refugios visitables de cada municipio; el nivel de uso actual de los refugios visitables; el nivel de uso potencial; la tarifa, si la hay, de acceso a cada refugio; los agentes implicados en la gestión de 
los refugios; y, por último, las acciones que se han llevado a cabo en cuanto a comunicación, protección, señalización e interpretación. En la segunda fase del estudio, propiamente basada en la inspección in situ, se ha procedido a la visita y documentación de los refugios antiaéreos accesibles al público a partir de la ficha anteriormente mencionada. En concreto, el trabajo de campo se llevó a cabo entre los meses de septiembre de 2019 y marzo de 2020 y ha permitido recolectar información más detallada para completar la base de datos, así como fotografiar el estado general de los 16 refugios. Por último, con la información empírica recabada, se procede a realizar un doble análisis estratégico de las variables externas e internas, mediante la herramienta de evaluación DAFO, y a contrastar la hipótesis inicial.

Este análisis estratégico nos permite conocer y evaluar sistemáticamente tanto el estado como la potencial evolución de los factores externos e internos involucrados en la puesta en valor turística de los refugios antiaéreos a partir de los recursos y capacidades existentes. El análisis DAFO es una herramienta de diagnóstico estratégico ampliamente utilizada que toma en consideración cuatro factores: dos relacionados con los aspectos internos del caso estudiado (Debilidades y Fortalezas), y otros dos con variables externas (Amenazas y Oportunidades) (Pahl y Richter, 2007).

\section{PATRIMONIO, MEMORIA Y TURISMO DE LA GUERRA CIVIL EN CATALUÑA}

Con el objeto de acotar la aproximación teórica a los refugios antiaéreos y su relación con el turismo, a continuación, se presenta el enfoque epistemológico escogido dentro de los estudios de turismo cultural: el turismo de memoria. Así mismo, también se exponen los principales atributos patrimoniales de los vestigios de la Guerra Civil española, y en particular se discute el valor histórico y social de los refugios antiaéreos desde la perspectiva de la gestión turística.

\subsection{Turismo patrimonial de memoria y políticas de gestión}

Este estudio sobre el modelo de valorización turística de los refugios antiaéreos de la provincia de Girona plantea un acercamiento analítico desde la perspectiva epistemológica del turismo de memoria. Otros modelos teóricos, tales como el Dark Tourism (Foley y Lennon, 1996), el Thanatourism (Seaton, 1996), o los planteamientos realizados desde el ámbito de la turistización de los espacios bélicos, también presentan elementos definitorios que permiten el análisis de las implicaciones turísticas de los refugios antiaéreos. Sin embargo, la relación con una incipiente estrategia de difusión turística encuadrada en el marco de unas políticas públicas de memoria, junto con la influencia existente del vecino modelo francés, permite formular la visión analítica del tourisme de mémoire como la más adecuada.

Por turismo de memoria se entienden aquellas prácticas turísticas desarrolladas en torno a los espacios patrimoniales de memoria que, sirviéndose de herramientas interpretativas de carácter didáctico, permiten al visitante conocer unos hechos históricos constitutivos de memoria colectiva. Con el desarrollo de esta modalidad turística patrimonial se promueven dos objetivos fundamentales: la educación cívica y la activación territorial (Bouliou, 2013). A través del "enrichissement civique et cultural que procure la référence au passé" (Cavaignac y Deperne, 2003, p.14), es posible hacer que el visitante pueda desarrollar unos valores relacionados con la paz y los derechos humanos, así como también permitir que el propio turista reconozca y acepte los hechos traumáticos de su pasado (Urbain, 2003). Del mismo modo, la utilización de patrimonios bélicos y memoriales en desuso puede favorecer 
el desarrollo económico de un territorio gracias al turismo (Da Silva y Bougon, 2013), fomentando también estrategias de "faire territoire" (Hertzog, 2013, p.56), así como la incentivación de valores identitarios a través de la implicación del habitante autóctono con dicho patrimonio. Este esquema ha sido aplicado a numerosos recursos patrimoniales territoriales comparables con el caso aquí estudiado, desde las ciertamente muy turistizadas playas del Desembarco y Batalla de Normandía (1944), durante la Segunda Guerra Mundial, hasta los espacios periféricos y menos desarrollados de la Batalla del Ebro (1938), durante la Guerra Civil española, en el sur de Cataluña. Sobre estos últimos, Andreu y Pujadas (2011) identifican eficientemente las dos caras del desarrollo del turismo de memoria en la zona, escenificadas en la activación turística local y la reivindicación de los valores democráticos.

Los elementos patrimoniales que participan de dichas prácticas turísticas son de naturaleza variada, pudiendo éstos ser clasificados como lugares conmemorativos, testimoniales o informativos y didácticos (González Vázquez, 2016). Entre los primeros se encuentran aquellos espacios monumentales o memoriales cuya función es honrar a determinados sujetos o colectivos. Los segundos serían aquellos espacios considerados como vestigios materiales, mientras que en el tercer grupo incluiríamos aquellos elementos que cuentan con alguna estrategia museográfica o discursiva in situ que permite su interpretación por parte del visitante. Según esta clasificación, los refugios antiaéreos estarían a caballo entre la segunda y la tercera categoría, puesto que su presencia atestigua la existencia de unos hechos históricos, a la vez que en determinados casos su puesta en valor se sirve de herramientas interpretativas (Figura 2).

Figura 2. Categorías de espacios para el turismo de memoria

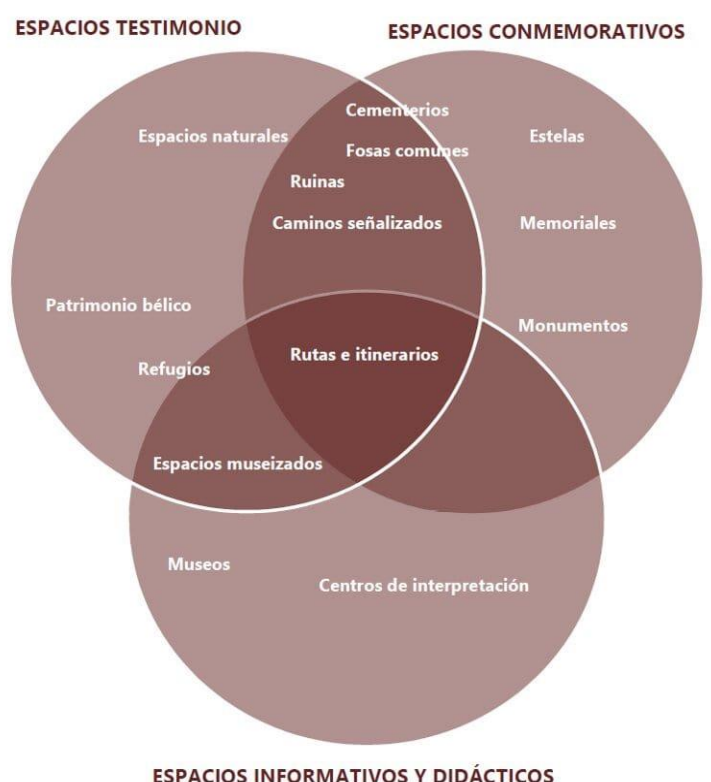

ESPACIOS INFORMATIVOS Y DIDACTICOS

Fuente: González Vázquez, 2016

Los orígenes del turismo de memoria han sido identificados a partir del final de la Primera Guerra Mundial (Da Silva y Bougon, 2013; Piernas, 2014). Los efectos devastadores de la Gran Guerra, con aproximadamente 10 millones de muertos, supusieron el origen de las conmemoraciones a gran escala (Edwards, 2000) e indujeron a las primeras prácticas de memoria, en relación al turismo, con las grandes peregrinaciones a los antiguos campos de batalla. Sin embargo, no es hasta la década de 1970 cuando se comienzan a poner en valor de 
manera regular los espacios patrimoniales de memoria, eclosionando definitivamente en los años 90 y siendo en la actualidad visitados por millones de personas alrededor de Europa (Mantei, 2012).

El patrimonio memorial, a partir del cual se desarrollan las prácticas y estrategias de difusión del turismo de memoria, se corresponde en el conjunto de España a aquellos vestigios relativos a la Guerra Civil y a la Dictadura franquista. Cataluña, a partir de la aprobación de la Llei del Memorial Democràtic en 2007 (Llei 13/2007, de 31 de octubre) y la creación del organismo que, con el mismo nombre, se encargaría de la promoción y divulgación de la memoria democrática a nivel autonómico, aplicó un plan de actuación para la identificación, clasificación y valorización de sus espacios de memoria. Quedaba así establecido que la memoria democrática adquiría la categoría de patrimonio (Vinyes, 2009, 2016) y, como tal, se acotó su ámbito cronológico de referencia entre 1931 y 1980. Del trabajo iniciado a partir del plan de actuación acabó perfilándose una estructura geográfica, organizativa y temática que debía funcionar a modo de red, la Xarxa d'Espais de Memòria Democràtica de Catalunya (en adelante XEMD).

A nivel territorial, los espacios de memoria incluidos en la red forman parte de alguna de las 42 comarcas en que se dividen las cuatro provincias de Cataluña, aunque existen circunscripciones en las que no hay ningún espacio catalogado. En lo referente al nivel organizativo, los conjuntos patrimoniales pertenecientes a la red están jerarquizados entre sedes y secciones. Las primeras son solamente 3 y son entidades que ejercen un grado de influencia notable en su ámbito de actuación: la propia sede del Memorial Democràtic en Barcelona, el Consorci Memorial dels Espais de la Batalla de l'Ebre (COMEBE) y el Museu Memorial de l'Exili (MUME). Las secciones están, a su vez, jerarquizadas en centros de referencia y espacios, según su grado de desarrollo patrimonial. Y con respecto al nivel temático, los espacios de memoria democrática de Cataluña están divididos en 4 grandes bloques: Segunda República, Guerra Civil, Frontera y exilio, y Lucha antifranquista y recuperación democrática. En este sentido, el caso aquí estudiado de los refugios antiaéreos forma parte de los espacios de la Guerra Civil.

El turismo de memoria en el conjunto del territorio de Cataluña puede considerarse heredero de las políticas de gestión patrimonial del Memorial Democràtic. Aunque es cierto que con anterioridad a la existencia de esta institución ya existían iniciativas de difusión turística del patrimonio de la Guerra Civil española (Santacana, 2004), será a partir de la consolidación de un relato común compartido entre todos los espacios patrimoniales de la memoria democrática de Cataluña cuando se puede hablar con rigor de la existencia de un modelo propio. El desarrollo de una estrategia de branding y de una metodología de señalización unificada y compartida por todos los enclaves patrimoniales incluidos en la red territorial facilita el reconocimiento del turismo de memoria en Cataluña. Éste existe, está ligado principalmente a los espacios de la Guerra Civil española y tiene en el relato de la memoria democrática su principal eje discursivo (González Vázquez, 2014, 2016).

\subsection{El patrimonio de la Guerra Civil en Cataluña y su puesta en valor turística}

La Guerra Civil ha sido, sin lugar a dudas, el acontecimiento que ha marcado de forma más determinante la historia política, social, cultural y sentimental de Cataluña y España en el siglo XX. Ya durante el conflicto se dieron algunas iniciativas turísticas de índole público y privado, tanto en el bando republicano como franquista, que consistían en visitar los frentes 
de batalla para conocer in situ los escenarios e instalaciones bélicos, y en general el devenir de un episodio que en aquel entonces se vivía con un auténtico sentido de trascendencia histórica. Se trataba, por tanto, de una modalidad a medio camino entre lo que hoy podríamos definir como turismo de guerra y turismo cultural (Brandis y Del Río, 2016). En la actualidad, aquellos hechos y paisajes, aunque lejanos en el tiempo, todavía poseen la capacidad de generar diferentes actitudes o estados emocionales en la sociedad actual, entre los que podemos destacar dos posturas antagónicas: el olvido -intencionado o no- y la rememoración y/o conmemoración. Existe, no obstante, otra postura, quizás la más preocupante y también, por desgracia, una de las más frecuentes en las generaciones nacidas en la España democrática: el desconocimiento y desinterés. Este hecho no resulta extraño si se tiene en consideración que el tema de la Guerra Civil, de sus consecuencias en el presente y de su legado material, a menudo se ha silenciado u omitido fuera del ámbito historiográfico y patrimonial, incluso en la educación obligatoria, singularmente durante el franquismo, pero también en la etapa democrática.

En este sentido, el turismo cultural, una actividad muy relevante en el modelo productivo español y catalán, ofrece una excelente oportunidad de reivindicación, valorización y acercamiento didáctico a este rico conjunto patrimonial. $Y$, en concreto, los refugios antiaéreos constituyen uno de los elementos más emblemáticos y, en ciertos casos, mejor conservados, especialmente en el subsuelo de ciudades y municipios de todo el territorio estatal.

En el siglo XXI, la oferta de atractivos vinculados a la Guerra Civil habilitados para su visita pública ha ido creciendo en diversos municipios catalanes y españoles, aunque todavía existen muchos enclaves de gran valor e interés que, por razones diversas, quedan fuera de las iniciativas y acciones de musealización y activación turística. Seguramente, cabría buscar las razones de ello en el hecho de que todavía no existe una línea de actuación patrimonial concreta y sistematizada, a nivel oficial y estatal, dirigida a la intervención, recuperación y divulgación de los restos materiales vinculados a uno de los episodios más trascendentales de la historia de España, como es la guerra del 36. Por esta razón, las iniciativas locales que se desarrollan en numerosos municipios a lo largo y ancho de la geografía española deben ser valoradas en su justa medida, como el caso aquí analizado de la provincia de Girona, por constituir acciones de gran valor divulgativo de la historia y la cultura, uno de los pilares de crecimiento sostenible establecidos por la UNESCO (O'Donnell, 2015). Pero también, como un valioso ámbito de investigación y aplicación de los preceptos teóricos, estrategias, métodos y técnicas propias de la disciplina turística, en su faceta relativa a la gestión del legado y hábitos culturales (Jafari, 2005).

Por su parte, desde el ámbito de la historia y la arqueología, en los últimos años se han realizado interesantes aportaciones teóricas y metodológicas en torno a la conceptualización, estudio y reivindicación social del patrimonio de la Guerra Civil (González Ruibal, 2016). En este sentido, se debe considerar como herencia cultural material de este período todos aquellos vestigios materiales relacionados con los hechos de 1936-1939, tanto bienes muebles como inmuebles, militares como civiles, del bando republicano como franquista. También es conveniente romper ciertos estereotipos establecidos en la sociedad y la esfera política y reivindicar que el patrimonio de la Guerra Civil no se limita a los monumentos conmemorativos o expiatorios, panteones, cenotafios y placas erigidos en calles y plazas, sino que conforma un conjunto mucho más amplio y diversificado cuyos restos se localizan en 
núcleos urbanos y entornos rurales, así como campos de batalla, líneas de trincheras, fortificaciones e instalaciones de servicio ubicados en el frente de guerra y, por esta razón, a menudo lejos de los principales circuitos turísticos (Romero, 2009).

A lo largo y ancho de la geografía catalana existen numerosos emplazamientos de estas características (Miró, 2013). Algunos son conocidos principalmente por los vecinos, otros tienen mayor visibilidad y cuentan con proyectos de activación turística. Sin embargo, un rasgo común a la mayor parte de este legado inmueble es que, desgraciadamente, se encuentra en un alarmante estado de abandono y desprotección, incluso a pesar de contar con el reconocimiento institucional por parte de la Generalitat de Catalunya de Bien de Interés Cultural (BIC). El conjunto patrimonial más destacado de espacios de la Guerra Civil en Cataluña es el que se vertebra alrededor de los escenarios de la Batalla del Ebro (julionoviembre de 1938) y su frente. Este episodio fue el más importante del conflicto que se desarrolló en tierras catalanas y ha dejado vestigios a lo largo de un área de cerca de $300 \mathrm{~km}^{2}$ entre los que se encuentran trincheras, nidos de ametralladora, estructuras defensivas y refugios, puestos de mando y observatorios militares, hitos conmemorativos y otras muchas tipologías. Además, existen otros escenarios relacionados con la contienda que preservan importantes restos materiales, como el frente de los ríos Segre y Noguera Pallaresa. También tuvieron un gran protagonismo durante la guerra los antiguos aeródromos de la comarca del Penedès (a caballo entre las provincias de Barcelona y Tarragona), que en algunos casos todavía conservan restos de refugios antiaéreos e instalaciones anexas.

Sin embargo, los refugios antiaéreos constituyen una de las tipologías patrimoniales mejor preservada y con mayor potencial turístico en Cataluña, aunque en algunos municipios el desarrollo urbanístico de los últimos decenios haya dañado, e incluso destruido, algunos conjuntos de gran valor. Un caso singular es el de la ciudad de Barcelona, que contaba con un censo de cerca de 1400 refugios al finalizar la guerra. De ellos se conservan varias docenas en el subsuelo y tan solo dos son visitables con regularidad desde la década pasada, una muestra demasiado irrelevante en el conjunto de la rica y variada oferta turística cultural de la capital y que no hace justicia a la trascendencia de este período en la historia de la ciudad (Besolí, 2004).

\section{LOS REFUGIOS ANTIAÉREOS EN LA PROVINCIA DE GIRONA}

En este apartado se analiza el caso de los refugios antiaéreos de la provincia de Girona desde el punto de vista de su valor histórico patrimonial y la situación de su aprovechamiento social, considerando en todo momento el punto de vista turístico y su potencial como atractivo cultural, educativo, y como activo dinamizador de la economía local.

\subsection{Valor histórico y social de los refugios antiaéreos}

Durante la Guerra Civil española se introdujo la táctica del bombardeo indiscriminado sobre poblaciones de retaguardia. En consecuencia, los refugios antiaéreos no sólo constituyen un testimonio de primera magnitud de aquel conflicto que asoló el país, sino que documentan un punto de inflexión crucial en la historia militar del siglo XX. De ahí su innegable interés histórico, patrimonial y su potencial valor didáctico que justifica, criterios económicos al margen, su incorporación a la oferta de los destinos turísticos en Cataluña y el resto de España, siempre y cuando sea viable en base a criterios de preservación, gestión y seguridad. 
Los bombardeos aéreos fueron utilizados indiscriminadamente por los dos bandos combatientes. Cataluña, como otras regiones de España, sufrió frecuentes bombardeos aéreos en su retaguardia desde febrero de 1937 (Gesalí e Iñíguez, 2012). Diversas localidades y ciudades recibieron las bombas, aunque en la literatura y en la memoria popular se recuerda por su crudeza especialmente los bombardeos de los días 16, 17 y 18 de marzo de 1938 en Barcelona, que se cobró un millar de vidas, o el Bombardeo de Granollers del 31 de mayo de ese mismo año, con más de doscientas víctimas mortales (Villarroya, 1999).

El organismo público que tomó la iniciativa de preparación de la defensa pasiva fue la Generalitat de Catalunya, en coordinación con los ayuntamientos de los diferentes municipios. Así, se creó una Junta de Defensa Pasiva, dependiente del gobierno catalán, y las Juntas de Defensa Locales, encargadas de las labores de protección de los edificios y enclaves importantes, así como de la construcción de los refugios públicos municipales. Sin embargo, en muchas localidades y grandes ciudades, como el caso de Barcelona, donde el tejido asociativo era importante, fueron los propios ciudadanos a través de las juntas y asociaciones vecinales los que se organizaron para conseguir los materiales necesarios y los conocimientos técnicos precisos para iniciar los trabajos de construcción subterránea de refugios. Allí donde tenían presencia, los partidos políticos y sindicatos también se sumaron a este movimiento social y de ingeniería sin precedentes (Pujadó, 2006).

Lo cierto es que, en un principio, los refugios tenían un carácter provisional, efímero, dado que era imposible prever la duración del conflicto. Sin embargo, con el tiempo, y ante la prolongación del mismo, en muchos municipios se comenzaron a planificar construcciones de protección civil más ambiciosas, más resistentes, mejor estructuradas y ventiladas y dotadas de servicios básicos. Algunas de ellas fueron concebidas para perdurar y ser reutilizadas como almacenes, baños públicos y otras instalaciones de uso diverso, una vez acabada la guerra. Aunque en su construcción participaba personal militar, sobre todo ingenieros y zapadores, el gran número de refugios construidos en el territorio de Cataluña se debe sobre todo a la iniciativa popular y al trabajo organizado de la población civil de retaguardia, incluyendo mujeres, niños y ancianos, así como personal no militarizado. No obstante, la Junta de Defensa Pasiva y las Juntas de Defensa Locales se encargaban de supervisar el transcurso de las obras y de dar el visto bueno (Pujadó, 2006, 2008, 2009). Muchas familias, a título particular, también habilitaron espacios en sótanos de casa y edificios para protegerse ante los bombardeos.

Los refugios municipales solían tener cuidadores que se encargaban de su mantenimiento, e incluso existían cuotas para este fin o para garantizarse asientos o ubicaciones específicas dentro de los mismos. Todas estas circunstancias que rodearon la vida en la retaguardia en los tiempos de guerra han quedado recogidas en documentos audiovisuales $y$, fundamentalmente, en los testimonios orales de las personas que vivieron aquellas trágicas circunstancias (Pujadó, 1998). Sin embargo, el hecho de haber conservado algunos de estos complejos permite rememorar aquellos acontecimientos, dinamizar social y económicamente los municipios que los albergan y, en última instancia, fomentar que las generaciones presentes y futuras puedan visitar estos refugios en tiempos de paz y conocer y reflexionar sobre las consecuencias de la guerra. 


\subsection{Conservación y puesta en valor turística}

A lo largo de la investigación se han podido constatar tres modelos básicos de gestión y valorización (social y turística) del patrimonio de la Guerra Civil y, específicamente, de los refugios antiaéreos, desde una perspectiva geográfica: el caso específico, el caso urbano y el caso territorial. El primer modelo, bien sea por su significación histórica u óptimo estado de conservación, es el paradigma más extendido en España y cuenta con algún ejemplo emblemático como el Refugio 307, en Barcelona ciudad, entre otros (Besolí y Peinado, 2008). Un segundo modelo consiste en la dinamización de un municipio o ciudad. Desde la promulgación en 2017 de la Ley de Memoria Democrática Valenciana, esta comunidad autónoma cuenta con los instrumentos legislativos adecuados para liderar este modelo urbano a nivel estatal, contando ya con algunas iniciativas municipales en la puesta en valor de los refugios antiaéreos destacables como los casos de Alicante y Valencia ciudad (Moreno y Sapena, 2017). Por último, el modelo territorial, que sería el que se corresponde con el caso aquí analizado, amplia el foco de interés a espacios más extensos para incluir comarcas, provincias o regiones mediante itinerarios. El proyecto ya mencionado de los espacios de la XEMD, impulsado en Cataluña por el Memorial Democràtic desde la administración autonómica, constituye un ejemplo paradigmático de esta modalidad, junto con algunas propuestas provenientes del ámbito académico, como en el caso de la Comunidad de Madrid (Navajas y González, 2017).

El presente análisis se enmarca en este tercer modelo de puesta en valor turística y abarca un territorio de aproximadamente $5.900 \mathrm{~km}^{2}$ de extensión, en el cual durante la Guerra Civil se construyeron 168 refugios, el 7 ' $88 \%$ del total de 2.131 que según la documentación de archivo existieron en toda Cataluña, de los cuales 16 centran el interés del estudio por su condición de visitables dentro de la oferta turística de la provincia de Girona (Abulí, 2015).

A partir de los datos actualizados recabados puede confirmarse que en 39 municipios gerundenses existen refugios antiaéreos conservados. Sin embargo, solamente en 10 de ellos han sido habilitados para la visita pública en condiciones de seguridad un total de 16 espacios, si bien es cierto que con estrategias de comunicación y recursos interpretativos dispares (Figuras 4 y 5). La distribución geográfica de estos 16 conjuntos patrimoniales visitables es la siguiente: [Campo de aviación de] Celrà (Celrà y Bordils) (5 refugios), [Campo de aviación de] Canet de la Tallada (La Tallada d'Empordà) (4 refugios), [Campo de aviación de] VilajuïgaGarriguella (Garriguella) (2 refugios), Campo de aviación de Martís (Fontcoberta) (1 refugio), Figueres ( 1 refugio), [Campo de aviación de] La Vall d'en Bas ( 2 refugios), Sant Feliu de Guíxols (1 refugio), Girona (1 refugio) y Roses (1 refugio). En los casos de Celrà, Bordils, Canet de la Tallada, Garriguella, Martís y la Vall d'en Bas, se trata de refugios ubicados en antiguos aeródromos de la aviación republicana (Gesalí, 2017). Cabe destacar que los 5 conjuntos del aeródromo de Celrà están repartidos entre los municipios de Celrà y Bordils, y que en el aeródromo de la Vall d'en Bas existen dos refugios abandonados que son accesibles por libre aunque no están categorizados como visitables por el Ayuntamiento dado el estado precario de la instalación. No obstante, en este estudio se han contabilizado como espacios viables con un claro potencial de atracción turística previa rehabilitación. 
Figura 3. Mapa de ubicación de los refugios visitables en la provincia de Girona (Escala $1: 500.000 \mathrm{~cm})$

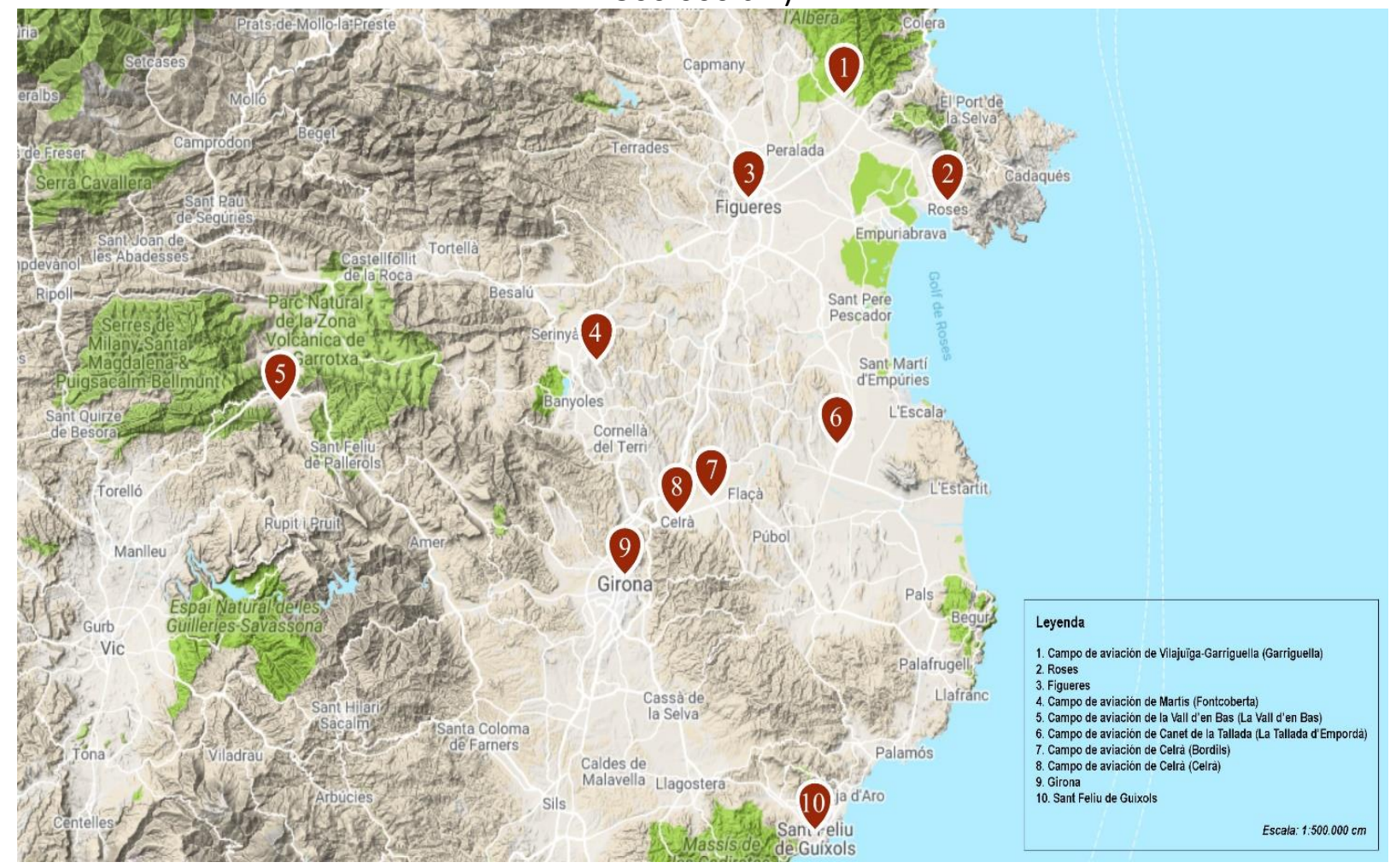

Fuente: Elaboración propia a partir de Google Maps 
Figura 4. Tabla resumen de los refugios visitables en la provincia de Girona Refugios visitables en la provincia de Girona

\begin{tabular}{|c|c|c|c|c|c|c|}
\hline $\begin{array}{l}\text { Nombre y } \\
\text { ubicación } \\
\text { del refugio }\end{array}$ & Estado & Uso & Interpretación & $\begin{array}{l}\text { Sistema de } \\
\text { protección }\end{array}$ & $\begin{array}{l}\text { Elementos de } \\
\text { comunicación }\end{array}$ & $\begin{array}{l}\text { Ratio de } \\
\text { refugios } \\
\text { visitables (en } \\
\text { la localidad) }\end{array}$ \\
\hline $\begin{array}{l}\text { Aeródromo } \\
\text { de Celrà }\end{array}$ & \multirow[t]{2}{*}{ Deficiente } & \multirow{2}{*}{$\begin{array}{l}\text { No regular, } \\
\text { bajo } \\
\text { demanda }\end{array}$} & \multirow[t]{2}{*}{ Alta (1) } & \multirow{2}{*}{$\begin{array}{l}\text { Plan Municipal } \\
\text { Especial de } \\
\text { Protección del } \\
\text { Patrimonio }\end{array}$} & \multirow[t]{2}{*}{$\begin{array}{l}(1),(3),(4),(6) y \\
(7)\end{array}$} & \multirow[t]{2}{*}{5 de 7} \\
\hline $\begin{array}{l}\text { Celrà y Bordils } \\
42.038187 \\
2.886266\end{array}$ & & & & & & \\
\hline $\begin{array}{l}\text { Aeródromo } \\
\text { Canet de la } \\
\text { Tallada } \\
\end{array}$ & \multirow{2}{*}{$\begin{array}{l}\text { Aceptable y } \\
\text { deficiente, } \\
\text { según } \\
\text { refugio }\end{array}$} & \multirow[t]{2}{*}{$\begin{array}{l}\text { No regular, } \\
\text { bajo } \\
\text { demanda }\end{array}$} & \multirow[t]{2}{*}{ Nula } & \multirow[t]{2}{*}{ Ninguno } & \multirow[t]{2}{*}{ (1), (3) y (5) } & \multirow[t]{2}{*}{4 de 6} \\
\hline $\begin{array}{l}\text { La Tallada } \\
\text { d'Empordà } \\
42.043607 \\
3.075877 \\
\end{array}$ & & & & & & \\
\hline $\begin{array}{l}\text { Aérodromo } \\
\text { de Vilajüiga- } \\
\text { Garriguella }\end{array}$ & \multirow[t]{2}{*}{$\begin{array}{l}\text { Aceptable y } \\
\text { deficiente, } \\
\text { según } \\
\text { refugio }\end{array}$} & \multirow[t]{2}{*}{ Regular } & \multirow[t]{2}{*}{ Media } & \multirow[t]{2}{*}{ Ninguno } & \multirow[t]{2}{*}{ (4) } & \multirow[t]{2}{*}{2 de 7} \\
\hline $\begin{array}{l}\text { Garriguella } \\
42.329105 \\
3.061824 \\
\end{array}$ & & & & & & \\
\hline $\begin{array}{l}\text { Aeródromo } \\
\text { Pla de Martis }\end{array}$ & \multirow[t]{2}{*}{ Bueno } & \multirow[t]{2}{*}{$\begin{array}{l}\text { No regular, } \\
\text { bajo } \\
\text { demanda }\end{array}$} & \multirow[t]{2}{*}{ Baja } & \multirow[t]{2}{*}{ Ninguno } & \multirow[t]{2}{*}{ (4) y (7) } & \multirow[t]{2}{*}{1 de 1} \\
\hline $\begin{array}{l}\text { Fontcoberta, } \\
42.154585 \\
2.765159\end{array}$ & & & & & & \\
\hline $\begin{array}{l}\text { Refugio de la } \\
\text { Placa del Gra }\end{array}$ & \multirow[t]{2}{*}{ Bueno } & \multirow[t]{2}{*}{$\begin{array}{l}\text { No regular, } \\
\text { bajo } \\
\text { demanda }\end{array}$} & \multirow[t]{2}{*}{ Alta (2) } & \multirow[t]{2}{*}{$\begin{array}{l}\text { Ninguno. } \\
\text { Mantenimiento } \\
\text { constante. }\end{array}$} & \multirow[t]{2}{*}{ (2) y (3) } & \multirow[t]{2}{*}{1 de 15} \\
\hline $\begin{array}{l}\text { Figueres } \\
42.266499, \\
2.965537 \\
\end{array}$ & & & & & & \\
\hline $\begin{array}{l}\text { Aeródromo } \\
\text { de la Vall } \\
\text { d'en Bas } \\
\end{array}$ & \multirow[t]{2}{*}{ Deficiente } & \multirow[t]{2}{*}{ Sin uso } & \multirow[t]{2}{*}{ Nula } & \multirow[t]{2}{*}{ Ninguno } & & \multirow{2}{*}{$\begin{array}{l}\text { o/2 de } 4 \text {. } \\
\text { Ninguno } \\
\text { categorizado } \\
\text { como visitable } \\
\text { desde el } \\
\text { municipio }\end{array}$} \\
\hline $\begin{array}{l}\text { La Vall d'en } \\
\text { Bas y Les } \\
\text { Preses } \\
42.136849 \\
2.454064 \\
\end{array}$ & & & & & & \\
\hline $\begin{array}{l}\text { Refugio del } \\
\text { Puig de Sant } \\
\text { Feliu }\end{array}$ & \multirow[t]{2}{*}{ Aceptable } & $\begin{array}{l}\text { No regular, } \\
\text { bajo } \\
\text { demanda }\end{array}$ & Nula & $\begin{array}{l}\text { Ninguno. } \\
\text { Mantenimiento } \\
\text { constante }\end{array}$ & (4) & $\begin{array}{l}1 \text { de } 10 . \\
\text { Parcialmente } \\
\text { visitable }\end{array}$ \\
\hline $\begin{array}{l}\text { Sant Feliu de } \\
\text { Guíxols } \\
41.783376 \\
3.028024 \\
\end{array}$ & & & & & & \\
\hline $\begin{array}{l}\text { Refugio El } \\
\text { Jardí de la } \\
\text { Infància }\end{array}$ & Aceptable & Regular & Alta $(1,2)$ & Ninguno & $\begin{array}{l}(1),(2),(3),(4),(5) \\
y(6)\end{array}$ & 1 de 6 \\
\hline $\begin{array}{l}\text { Girona } \\
41.980992 \\
2.824274 \\
\end{array}$ & & & & & & \\
\hline $\begin{array}{l}\text { Refugio de la } \\
\text { Pau }\end{array}$ & Aceptable & Regular & Alta (2) & $\begin{array}{l}\text { Bien Cultural } \\
\text { de Interés } \\
\text { Local. }\end{array}$ & $(1),(2),(3)$ y $(5)$ & $\begin{array}{l}1 \text { de } 5 . \\
\text { Parcialmente } \\
\text { visitable }\end{array}$ \\
\hline $\begin{array}{l}\text { Roses } \\
42.263831 \\
3.175382\end{array}$ & & & & $\begin{array}{l}\text { Generalitat de } \\
\text { Catalunya }\end{array}$ & & \\
\hline
\end{tabular}

Elaboración propia 
Figura 5. Leyenda de categorías de los refugios visitables en la provincia de Girona Leyenda sobre categorías de los refugios visitables en la provincia de Girona

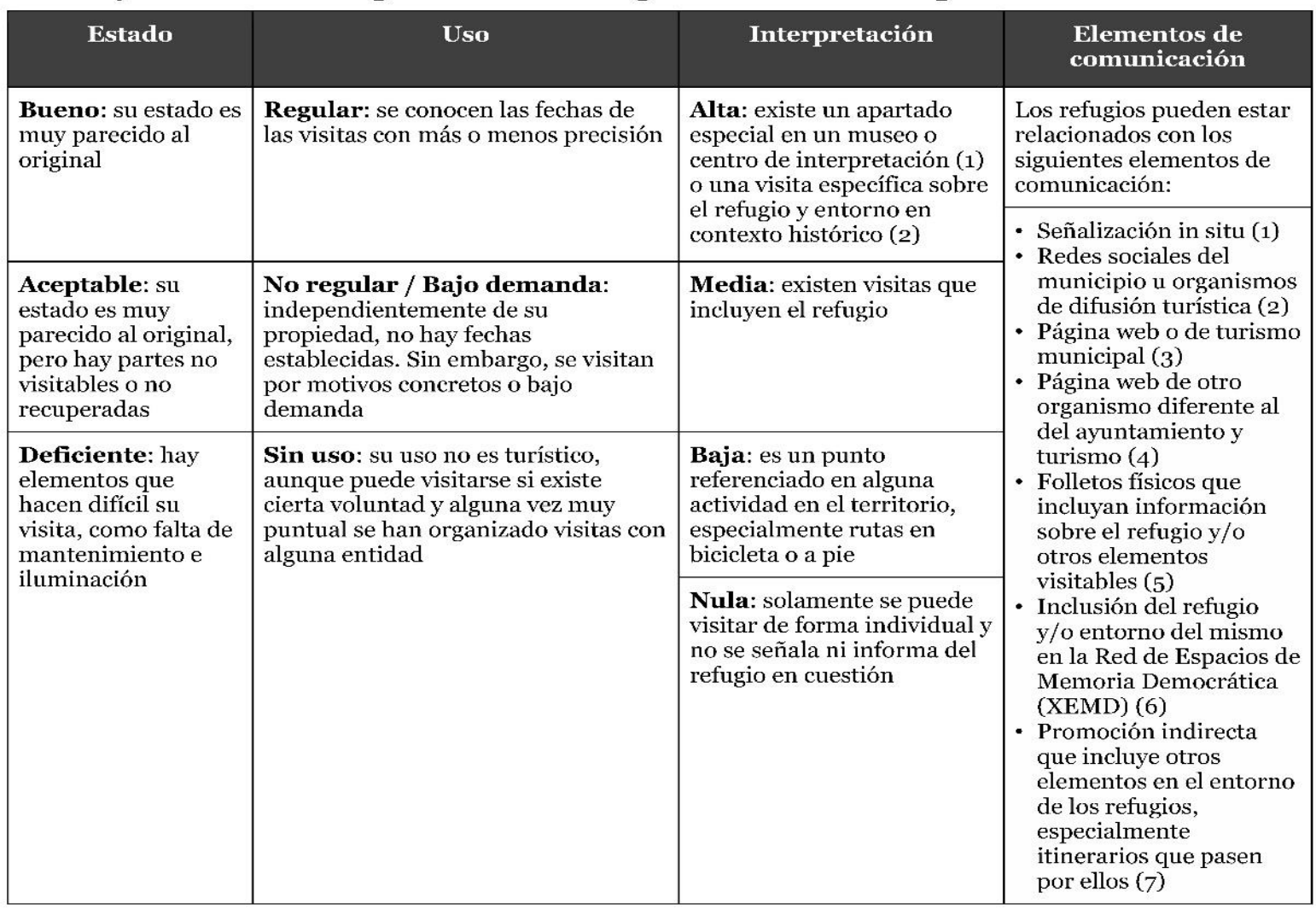

Elaboración propia

En los 29 municipios restantes, los refugios antiaéreos que han pervivido hasta nuestros días no son accesibles al público. Este es el caso de las localidades de Agullana, Alp, Anglès, Banyoles, Blanes, Boadella d'Empordà, Cabanes, Cassà de la Selva, Colera, Colomers, El Far d'Empordà, El Port de la Selva, Esponellà, L'Escala, La Selva de Mar, Llançà, Massanes, Ogassa, Olot, Palafrugell, Palamós, Portbou, Puigcerdà, Ripoll, Santa Llogaia d’Àlguema, Tortellà, Tossa de Mar y Vidreres. El estado de conservación de estos espacios patrimoniales es, en general, muy deficiente y por esta razón los accesos permanecen tapiados. En definitiva, solo en un tercio del total de municipios gerundenses donde existen refugios antiaéreos de la Guerra Civil se puede hablar de medidas de activación turística efectivas o con un potencial realista.

En cuanto a la gestión y puesta en valor de los refugios visitables es posible constatar diferentes tendencias o situaciones que condicionan su visibilidad social. Por ejemplo, municipios con una fuerte actividad turística como Roses o Girona capital disponen de medios para poder promocionar sus refugios en clave turística, aunque éstos sigan sin ser parte relevante de su oferta frente a otros atractivos culturales. Otras poblaciones, como Celrà y Bordils, pese a ser municipios de pequeño tamaño, han apostado fuerte por la valorización de sus refugios, asociados a un espacio patrimonial de mayor extensión y relevancia como es el antiguo aeródromo, infraestructura militar clave en la contienda. En otros casos, como en Tortellà, en la comarca de La Garrotxa, la negativa de la propiedad del refugio, de titularidad privada, imposibilita cualquier iniciativa de puesta en valor. Por último, en Palamós, el municipio con mayor número de refugios conservados con un total de 22 , se da un caso 
singular ya que el único espacio que estaba abierto al público y a centros educativos, gestionado por el Servicio del Archivo Municipal (SAMP), en el momento de redactar este artículo ya no se puede visitar debido a un informe técnico del arquitecto municipal que desaconseja su uso civil.

Con respecto a los elementos de comunicación, en la mayoría de los espacios existe señalización interpretativa in situ, con datos históricos e información visual, y folletos informativos en diferentes idiomas. Además, algunos refugios cuentan también con presencia en internet, fundamentalmente mediante páginas web que facilitan datos de interés patrimonial y turístico, como ubicación, medios de transporte y horarios (Figura 4). En este sentido, destaca el caso del refugio del Jardí de la Infància de Girona, el cual añade códigos QR (Quick Response) en la señalización, para ampliar la información mediante dispositivos móviles, y también cuenta con un entorno web en el cual se puede realizar una visita virtual mediante fotografías envolventes de 360‥

En los casos de los antiguos aeródromos se dan diferentes tipos de gestión turística. Por ejemplo, en Celrà y Canet de la Tallada son los propios municipios los que gestionan las visitas y señalizaciones del campo de aviación. En Garriguella se da una participación pública y privada, ya que la promoción de las visitas se hace tanto desde Empordà Turisme como desde la bodega Mas Llunes. Sin embargo, el caso del aeródromo de Fontcoberta es especial: pese a estar ubicado en dicho término municipal, para realizar la visita del refugio se debe concertar previamente con el ayuntamiento de la localidad de Porqueres, el cual dispone de una llave y permite el acceso de manera acordada con el propietario del terreno (Ejarque y Rustullet, 2009). En la gran mayoría de conjuntos estudiados se hace evidente la necesidad de una mayor regularización de las visitas, con unos horarios estables que faciliten la planificación por partes de los potenciales visitantes.

\subsection{Análisis estratégico turístico}

Tras ejecutar las acciones metodológicas de carácter cualitativo presentadas con anterioridad (estudio de fuentes, entrevistas y trabajo de campo), se plantea un análisis estratégico para investigar el vigente contexto turístico-cultural de los refugios antiaéreos de Girona y su potencial de atracción, fundamentalmente de aquellos que no han sido abiertos al público o integrados en la oferta cultural de la provincia al finalizar la presente investigación. La hipótesis de partida, formulada a partir de los conocimientos obtenidos por el equipo de trabajo durante la observación y estudio de campo de otros casos análogos de conjuntos patrimoniales defensivos relacionados con el conflicto bélico en Cataluña, España y Europa occidental durante más de una década, propugna que la puesta en valor turística eficaz y sostenible de este valioso conjunto patrimonial del siglo XX es viable y factible con voluntad política y la implicación de los agentes turísticos locales y autonómicos. Además, se considera, como se ha razonado en apartados anteriores, que la dinamización turística de los refugios no solamente añade un importante activo a la oferta turística cultural ya existente, sino que además constituye una importante contribución a la divulgación y educación sobre la historia

\footnotetext{
${ }^{1}$ Véase: Museu d'Història de Girona. Visita virtual al refugio del Jardí de la Infància (Refugio antiaéreo 38): https://www.girona.cat/museuhistoria/refugivisita/index.html.
} 
de la Guerra Civil española, así como a la difusión de los valores asociados a la cultura de la paz y la convivencia democrática.

El análisis propuesto se basa en una herramienta cualitativa ampliamente utilizada en la investigación turística, así como en la formulación de estrategias de desarrollo para destinos turísticos: la matriz DAFO (Goranczewski y Puciato, 2010).

\subsubsection{Análisis DAFO}

La matriz DAFO nos permite observar los factores internos (Debilidades y Fortalezas) y externos (Amenazas y Oportunidades) relacionados con los refugios y su valorización y dinamización turística. Se trata de una técnica de análisis estratégico con vocación de recorrido, ya que puede ser reelaborada a lo largo del tiempo para constatar qué factores han evolucionado y en qué sentido (Goranczewski y Puciato, 2010). Con la matriz DAFO se ha recabado datos cualitativos que permiten conocer la situación real en la que se encuentran los refugios antiaéreos, en este caso desde una perspectiva turística patrimonial. Los factores analizados se presentan a continuación (Figura 6).

Figura 6. Análisis estratégico turístico mediante matriz DAFO

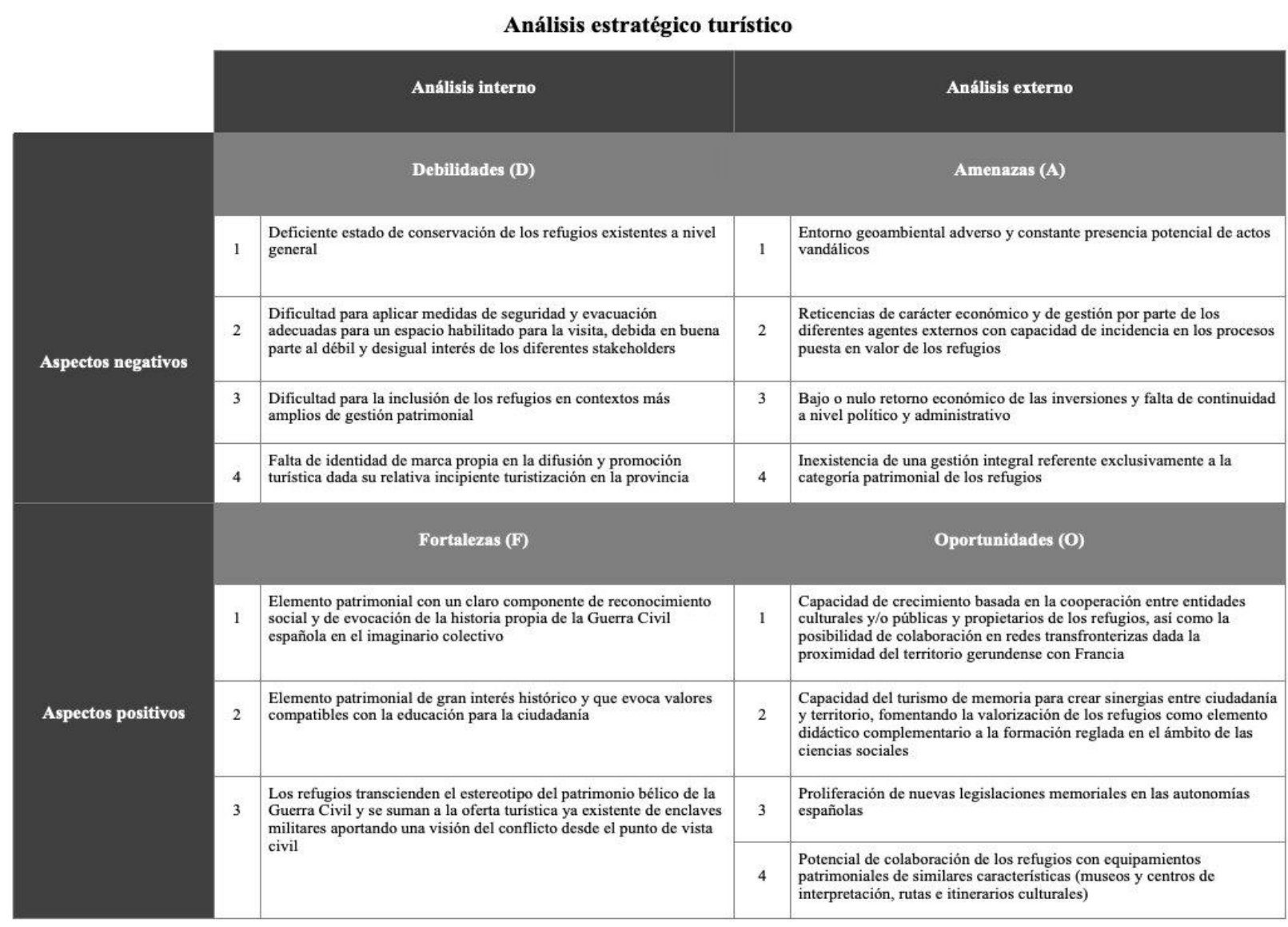

Elaboración propia 


\subsubsection{Análisis interno: Debilidades y Fortalezas}

Resulta evidente, dada la cronología del patrimonio en cuestión, que el estado de conservación de la mayoría de los refugios en la provincia de Girona es deficiente fruto del paso del tiempo y un abandono social importante durante décadas (D1). Este hecho se constata no solo en los refugios conservados clausurados, sino incluso en tramos o partes significativas de los conjuntos rehabilitados para su visita. Es un factor inherente a la naturaleza del patrimonio en cuestión, puesto que su función no era perdurar en el tiempo sino la protección inmediata durante el transcurso del conflicto. Al mismo tiempo, este hecho está en conexión con el grado de implicación de los agentes involucrados en su puesta en valor turístico, dado que esta acción implica un estudio arquitectónico previo (véase el caso de Palamós, refugio actualmente no visitable debido a un informe de estas características) y, en su caso, un proceso de rehabilitación para restaurar la integridad del conjunto histórico (si ha sufrido daños con el paso del tiempo) y proveer unas condiciones de visita óptimas (seguridad, iluminación, ventilación y señalización) (D2). Todo esto conlleva unos costes que, en el contexto general de crisis económica de la última década, no siempre resultan viables ni prioritarios. A todo ello se suma la dificultad de incluir los refugios en contextos más amplios de gestión patrimonial, hecho que se explica en buena medida por la falta de una gestión integral en sus políticas de difusión y, tal y como se ha discutido con anterioridad, el difícil equilibrio existente entre gestión pública y titularidad privada (D3).

La investigación también ha puesto de manifiesto que el incipiente recorrido como conjunto patrimonial visitable de los refugios en la provincia en los últimos años y su falta de identidad de marca en el sector turístico gerundense (D4) contrastan con su amplio reconocimiento social (F1) y su incuestionable valor histórico y patrimonial, tanto a nivel de percepción ciudadana (evocación de la historia propia) como de reflexión crítica sobre ciertos valores (cultura de la paz, convivencia y democracia) (F2). Por otra parte, los refugios antiaéreos constituyen una tipología bien definida dentro del legado inmueble de la Guerra Civil española, que trasciende el estereotipo del patrimonio bélico (campos de batalla, líneas de trincheras, fortificaciones militares) y ofrece una visión con un elevado grado de empatía (claustrofobia, incertidumbre, pánico) del impacto de la guerra en la población civil a través de las prácticas de defensa pasiva (F3).

\subsubsection{Análisis externo: Amenazas y Oportunidades}

Una de las debilidades anteriormente mencionadas (D1) es consecuencia directa del deterioro general de los refugios, fundamentalmente por los efectos del paso del tiempo y eventuales actos vandálicos $y$, en algunos casos, de la falta de implicación en su mantenimiento por parte de los agentes propietarios (A1). Sirva como ejemplo el refugio antiaéreo de Olot, que, tras estar abierto durante un tiempo las $24 \mathrm{~h}$ del día, tuvo que ser clausurado a causa de los diferentes usos ilícitos llevados a cabo en su interior. A este factor cabe sumar el elevado coste necesario para su puesta en valor de una forma segura y eficaz desde el punto de vista turístico y didáctico (A2), lo cual generalmente conlleva trabajos de rehabilitación arquitectónica e instalación de medidas que garanticen la seguridad del visitante, tales como sistemas de iluminación, pasarelas (Figura 1) y pasamanos que ayuden a salvar escaleras o desniveles, sin olvidar los costes de producción de los medios museográficos 
y/o interpretativos que, en su caso, se estimen oportunos. Este aspecto contrasta con el bajo o incluso nulo retorno de las inversiones realizadas en estos equipamientos memoriales, una de las opiniones recurrentes en la muestra de entrevistados. Al mismo tiempo, se constata la existencia de una dificultad añadida en la falta de continuidad política e institucional en la gestión a largo plazo de los refugios (A3). Tampoco se debe perder de vista la lógica con la cual los refugios antiaéreos fueron diseñados y construidos. Eran espacios, muchos de ellos subterráneos, pensados para la protección temporal ante los ataques aéreos, y por tanto su puesta en valor turística conlleva reconvertirlos en espacios habilitados para la visita regular, sorteando las limitaciones estructurales propias de la ingeniería de guerra y la inexistencia de una gestión integral que favorezca la ejecución de medidas específicas de conservación en los refugios (A4).

Del análisis de los factores tanto internos como externos que condicionan la activación turística de los refugios se desprende una serie de oportunidades estratégicas que determinan el gran potencial de este singular conjunto patrimonial. Por un lado, la situación actual deja margen al fomento de una comunicación más eficiente entre las entidades relacionadas con su gestión patrimonial y turística y los propietarios de los refugios, incluso estudiando la viabilidad de proyectos comunes con otros enclaves de la Guerra Civil transfronterizos (01). Desde el punto de vista educativo, los refugios pueden resultar un valioso activo patrimonial en el contexto de la educación formal e informal por medio de visitas escolares y de grupos de adultos, convirtiendo el turismo de memoria en un potenciador identitario entre la ciudadanía y el territorio (O2). En los últimos años, además, en el conjunto de comunidades autónomas españolas se ha dado un proceso creciente de legislación en favor de la protección y difusión del patrimonio de la Guerra $\mathrm{Civil}^{2}$, instrumento fundamental para una mayor visibilización y turistización de los refugios, tanto a nivel nacional como de la provincia de Girona (O3) que, además, sirve de marco para impulsar potenciales colaboraciones con otros equipamientos y proyectos patrimoniales memoriales a nivel local, provincial y autonómico (04).

\section{DISCUSIÓN DE RESULTADOS Y CONCLUSIONES}

Los datos recabados, tanto a partir de las entrevistas a expertos como del trabajo de campo, permiten contrastar y validar la hipótesis formulada en el presente estudio. Los refugios antiaéreos de la provincia de Girona constituyen un patrimonio que se ha comenzado a activar turísticamente de manera eficaz, pero que aún puede alcanzar un mayor desarrollo a partir de una gestión integral por parte del conjunto de agentes implicados.

El análisis que aquí se presenta evidencia este potencial de crecimiento, constatable en una serie de Fortalezas y Oportunidades bien definidas. Sin embargo, también es cierto que existen Debilidades y Amenazas significativas que conllevan retos estrechamente vinculados al contexto actual de crisis económica. Así, tal y como manifiestan 19 de las 30 personas entrevistadas en el presente estudio, se resalta la necesidad de realizar una importante inversión en trabajos de rehabilitación y adecuación (D1) cuyo retorno suele ser bajo o nulo y además no constituye una prioridad estratégica (A3). En este sentido, existe un

\footnotetext{
2 Sobre las diferentes legislaciones en materia de memoria histórica y democrática y sus implicaciones patrimoniales, véase: En Navarra: Ley Foral 33/2013; en el País Vasco: Ley 4/2014; en las Islas Baleares: Ley 10/2016; en Andalucía: Ley 2/2017; en la Comunidad Valenciana: Ley 14/2017; en Aragón: Ley 14/2018; y en Extremadura: Ley 1/2019.
} 
alto grado de deterioro general en el conjunto de refugios que han permanecido accesibles hasta la actualidad. Esto puede explicarse en buena medida por la indecisión a la hora de recuperar y mantener estos espacios patrimoniales por parte de los diversos agentes en posesión de su propiedad a causa de la baja rentabilidad. En cierto modo, esta postura se explica por la carencia de un apoyo institucional y económico estable por parte de la administración autonómica, cuyos vaivenes políticos en la última década han discontinuado la estrategia de valorización turística iniciada con la creación de la Xarxa d'Espais de Memòria Democràtica (Menéndez, 2011; González y Riera, 2018).

A esto cabe añadir el devastador impacto de la pandemia COVID-19 en el sector turístico internacional durante el año 2020. En el momento de redactar este artículo, existe una gran incertidumbre social y económica ante la evolución de la pandemia que, evidentemente, también afecta al turismo cultural gerundense. Fundamentalmente, porque la bajada del flujo de visitas motivada por las restricciones económicas y sanitarias presenta un complicado escenario para museos y equipamientos memoriales de todo tipo, comprometiendo además su situación financiera.

La perspectiva de mejora de los refugios antiaéreos de Girona, sin embargo, es amplia por diversos motivos. Tal y como afirman 27 de las 30 personas entrevistadas, existe una cada vez mayor concienciación social con respecto al patrimonio de la Guerra Civil y el valor didáctico de sus espacios de memoria. Una ciudadanía concienciada es el primer requerimiento para que exista un contexto dentro del cual puedan emerger sectores que actúen como emprendedores de memoria (Jelin y Langland, 2003), tan necesarios para desencadenar una posterior actuación a cargo de la administración. La administración catalana cuenta con la ventaja de disponer de una sólida base, con amplio recorrido y experiencia, en la difusión de sus espacios de memoria a través de la estructura de la XEMD. Una reactivación solvente de la misma sin duda debería contar con nuevos entes de gestión colaborativa de carácter temático en la que los refugios antiaéreos deberían tener un protagonismo importante.

Finalmente, la oportunidad de crecimiento de un turismo de memoria, cada vez más consolidado dentro de la rica oferta de turismo cultural de Girona, se hace aún más presente teniendo en cuenta la proximidad del territorio francés (González y Font, 2016; Font et al., 2016, González Vázquez, 2017, 2018b, 2019). El país galo ofrece un espejo de buenas prácticas en el ámbito del patrimonial, turístico y memorial, y enlazar con sus redes de trabajo y gestión puede suponer un avance en aras del objetivo principal al cual ceñirse para consolidar el crecimiento de los refugios antiaéreos como elemento de uso turístico: la gestión integral. Los diferentes depositarios de la propiedad de los refugios, tanto particulares como ayuntamientos; los consejos comarcales, con amplias competencias en la promoción turística del territorio; empresas dinamizadoras del sector patrimonial y turístico; los varios equipamientos culturales y museísticos del área de influencia y, sobre todo, la administración autonómica, tienen un rol importante que jugar en la activación turística de un patrimonio con un extraordinario valor histórico.

\section{REFERENCIAS BIBLIOGRÁFICAS}

Abulí, O. (2015). Els refugis antiaeris a les comarques gironines: un producte turístic de memòria incipient. Temps $i$ espais de memòria. Revista digital del Memorial Democràtic, 3, 52-57. 
Andreu, A. y Pujadas, J.J. (2011). El turismo de memoria: la patrimonialización de la memoria histórica en Catalunya. El proyecto "Más allá de una batalla" (La batalla del Ebro, Gandesa). En L. PRATS y A. SANTANA (Coords.), Turismo y patrimonio: entramados narrativos (pp. 271-287). El Sauzal (Tenerife): ACA y Pasos.

Besolí, A. (2004). Los refugios antiaéreos de Barcelona: pasado y presente de un patrimonio arcano. Ebre 38. Revista Internacional de la Guerra Civil (1936-1939), 2, 181-202.

Besolí, A. y Peinado, J. (2008)- El estudio y puesta en valor de los refugios antiaéreos de la Guerra Civil española: el caso del Refugio-Museo de Cartagena. ArqueoMurcia. Revista Electrónica de Arqueología de la Región de Murcia, 3. Recuperado de: https://www.museosregiondemurcia.es/documents/1806272/1815041/refugio cart agena.pdf/4e97ea6e-126d-49a6-8857-fd1bb86e7604?version=1.0

Bouliou, C. (2013). Du tourisme des batailles au tourisme des mémoires. Cahier Espaces, 313, 68-71.

Brandis, D. y Del Río, I. (2016). Turismo y paisaje durante la guerra civil española, 1936-1939. Scripta Nova. Revista Electrónica de Geografía y Ciencias Sociales, XX, 530. Recuperado de: http://revistes.ub.edu/index.php/ScriptaNova/article/view/530/18895.

Cavaignac, F. y Deperne, H. (2003). Les Chemins de mémoire. Une initiative de l'État. Cahier Espaces, 80, 12-21.

Da Silva, M. y Bougon, L. (2013). Le tourisme de mémoire. Un enjeu civique, pédagogique, économique et culturel pour la France. Cahier Espaces, 313, 48-51.

Edwards, P. (2000). "Mort pour la France": Conflict and commemoration in France after the First World War. University of Sussex Journal of Contemporary History, 1, 1-11.

Ejarque, J. y Rustullet, M. (2009). El refugi antiaeri de la Casa Nova d'en Traver. Revista de Girona, 254, 102-103.

Donaire, J.A. (2012). El turismo cultural: entre la experiencia y el ritual. Bellcaire d'Empordà (Girona): Ediciones Vitel·la.

Foley, M. y Lennon, J. (1996). Editorial: Heart of Darkness. Journal of International Heritage Studies, 2 (2), 195-197.

Font, J.; González, D.; Domènech, G. y Marquès, S. (2016). La memoria del exilio republicano a través de sus espacios: patrimonio, turismo y museos en el territorio catalán transfronterizo. En I. Arrieta (Ed.), Lugares de memoria traumática. Representaciones museográficas de conflictos políticos y armados (pp. 71-98). Bilbao: UPV/EHU Servicio Editorial.

Gesalí, D. (Coord.). (2017). Aeròdroms republicans de Girona. Atac i defensa des de la rereguarda. Viladamat (Girona), Gorbs Edicions.

Gesalí, D. e Íñiguez, D. (2012). La guerra aèria a Catalunya (1936-1939). Barcelona: Rafael Dalmau.

González, D. y Font, J. (2016). La museización del patrimonio memorial transfronterizo: el caso del exilio republicano y sus espacios. MIDAS - Museus e estudos interdisciplinares, 6. https://doi.org/10.4000/midas.1030 
González, D. y Mundet, L. (2018). Lugares de memoria traumática y turismo: paradigmas analíticos y problemáticas. Investigaciones turísticas, 16, 108-126.

González, D. y Riera, F. (2018). Girona Terra Memorial. Espais de Memòria i turisme a les comarques gironines. Girona: Patronat de Turisme Costa Brava - Pirineu de Girona.

González Ruibal, A. (2016). Volver a las trincheras: una arqueología de la Guerra Civil española. Madrid: Alianza.

González Vázquez, D. (2014). La práctica turística como mecanismo de transmisión de valores: Cataluña y los lugares de memoria democrática. RITUR - Revista Iberoamericana de Turismo, 4 (especial), 36-49.

González Vázquez, D. (2016). La patrimonialización de la memoria histórica: entre el deber social y la estrategia turística. Apuntes sobre el caso catalán. PASOS - Revista de Patrimonio y Turismo Cultural, 14 (5), 1267-1280.

González Vázquez, D. (2017). El turismo de memoria y las implicaciones de la frontera: una aproximación teórica desde los Pirineos. En R. Arnabat y M. Duch (Eds.), Polítiques memorials, fronteres $i$ turisme de memòria (pp. 97-114). Perpinyà/Tarragona: PUP/URV publicacions.

González Vázquez, D. (2018a). Dark tourism and Memorial tourism: nexus and divergences between theoretical models. European Journal of Tourism Research, 20, 46-58.

González Vázquez, D. (2018b). Les rutes de l'exili del MUME: una dècada connectant espais de memòria a la Catalunya transfronterera. Ebre 38. Revista Internacional de la Guerra Civil (1936-1939), 8, 279-308.

González Vázquez, D. (2019). Espais de memòria i turisme a la Catalunya transfronterera. Revista d'Etnologia de Catalunya, 44, 70-77.

Goranczewski, B. y Puciato, D. (2010). SWOT Analysis in the Formulation of Tourism Development Strategies for Destinations. Tourism, 20 (2), 45-53.

Guixé, J. (2008). El Memorial Democrático y los lugares de la memoria: la recuperación del patrimonio memorial en Cataluña. Entelequia, 7, 217-228.

Guixé, J. (2009). Espacios, memoria y territorio, un memorial en red en Cataluña. En R. Vinyes (Ed.), El Estado y la memoria: Gobiernos y ciudadanos frente a los traumas de la historia (pp. 569-608). Barcelona: RBA Libros.

Hertzog, A. (2013). Quand le tourisme de mémoire bouleverse le travail de mémoire, Cahier Espaces, 313, 52-61.

ICOMOS (1976). Carta de turismo cultural. París: ICOMOS. Recuperado de: https://www.icomos.org/charters/chartes.pdf.

Jafari, J. (2005). El turismo como disciplina científica. Política y Sociedad, 42 (1), 39-56.

Jelin, E. y Langland, V. (Comps.). (2003). Monumentos, memoriales y marcas territoriales. Madrid - Buenos Aires: Siglo XXI. 
Ley 52/2007, de 26 de diciembre, por la que se reconocen y amplían derechos y se establecen medidas en favor de quienes padecieron persecución o violencia durante la guerra civil o la dictadura.

Ley Foral 33/2013, de 26 de noviembre, de reconocimiento y reparación moral de las ciudadanas y ciudadanos navarros asesinados y víctimas de la represión a raíz del golpe militar de 1936.

Ley 4/2014, de 27 de noviembre, de creación del Instituto de la Memoria, la Convivencia y los Derechos Humanos.

Ley 2/2017, de 28 de marzo, de Memoria Histórica y Democrática de Andalucía.

Ley 14/2018, de 8 de noviembre, de memoria democrática de Aragón.

Ley $1 / 2019$, de 21 de enero, de memoria histórica y democrática de Extremadura.

Llei 13/2007, del 31 d'octubre, del Memorial Democràtic.

Llei 10/2016, de 13 de juny, per a la recuperació de persones desaparegudes durant la Guerra Civil $i$ el franquisme.

Llei 14/2017, de 10 de novembre, de la Generalitat, de memòria democràtica i per la convivència de la Comunitat Valenciana.

Mantei, C. (Dir.). (2012). Le tourisme de mémoire en France: mesure et analyse du poids et des retombées economiques et de la filière. París: Atout France.

Menéndez, F. (2011). Els centres i els Espais de Memoria Democràtica a Catalunya. Mnemosine: revista catalana de museologia, 6, 35-52.

Moreno, A. y Sapena, T. (2017). Refugis antiaeris: patrimoni de la Guerra Civil a la ciutat de València. Debats, Revista de Cultura, Poder i Societat, 131 (2), 123-140.

Navajas, O. y González, J. (2017). Turismo en espacios de conflicto. Análisis de la puesta en valor del patrimonio de la Guerra Civil Española en la Comunidad de Madrid. Methaodos. Revista de Ciencias Sociales, 5 (1), 155-172.

Miró, O. (2013). Restes i vestigis de la Guerra Civil: 17 rutes per Catalunya. Valls (Tarragona): Cossetània.

O'Donnell, P. (2015). Historic urban landscape: A new UNESCO tool for a sustainable future. En K. Taylor; A. St. Clair y N.J. Mitchell (Eds.), Conserving cultural landscapes: challenges and new directions (163-181). New York: Routledge.

Pahl, N. y Richter, A. (2007). SWOT Analysis. Idea, Methodology and a Practical Approach, Scholarly Research Paper, Norderstedt (Germany): GRIN Verlag.

Piernas, G. (2014). Les pèlerinages dans les régions dévastées du nord de la France organisés par la Compagnie du chemin de fer du Nord au lendemain de la Première Guerre mondiale. In Situ. DOI : 10.4000/insitu.11420.

Pujadó, J. (1998). Oblits de rereguarda: els refugis antiaeris a Barcelona, 1936-1939. Barcelona: Publicacions de l'Abadia de Montserrat.

Pujadó, J. (2006). Contra l'oblit: els refugis antiaeris poble a poble. Barcelona: Publicacions de l'Abadia de Montserrat. 
Pujadó, J. (2008). El llegat subterrani: els refugis antiaeris de la Guerra Civil. Badalona: Ara Llibres.

Pujadó, J. (2009). Els refugis antiaeris gironins. Revista de Girona, 254, 92-101.

Richards, G. (2002). Tourism attraction systems: Exploring cultural behavior. Annals of Tourism Research, 29 (4), 1048-1064.

Romero, E. (2009). Lugares de memoria e itinerarios de la Guerra Civil española: guía del viajero curioso. Barcelona: Laertes.

Santacana, J. (2004). Entre l'oblit i la memòria: el patrimoni de la guerra. Ebre 38. Revista Internacional de la Guerra Civil (1936-1939), 2, 169-180.

Saz, I. (2007). El "moment memòria". Justícia, veritat i reconciliació democràtica. En A. Colomines y J. Villarroya (Coords.), Història i memòria del segle XX (pp. 27-40). Catarroja (Valencia): Editorial Afers.

Seaton, A.V. (1996). Guided by the dark: From thanatopsis to thanatourism. Journal of Heritage Studies, 2 (4), 234-244.

Silva, E. (2011). Movimiento memorialista (El contexto de la memoria). En R. Escudero (Coord.), Diccionario de memoria histórica. Conceptos contra el Olvido (pp. 69-75). Madrid: Los Libros de la Catarata.

Timothy, D.J. (2011). Consumption of culture: heritage demand and experience. Cultural heritage and tourism. An introduction (pp. 15-45). Bristol, UK: Channel View Publications

Urbain, J.D. (2003). Tourisme de mémoire. Un travail de deuil positif. Cahier Espaces, 80, 5-7.

Velasco, M. (2009). Gestión turística del patrimonio cultural: enfoques para un desarrollo sostenible del turismo cultural. Cuadernos de Turismo, 23, 237-253.

Vinyes, R. (2009). La memoria del Estado. En R. Vinyes (Ed.), El Estado y la memoria: gobiernos y ciudadanos frente a los traumas de la historia (pp. 23-66). Barcelona: RBA Libros.

Vinyes, R. (2016). Memoria, democracia y gestión. História e Perspectivas, 54, 11-22.

Villarroya, J. (1999). Els bombardeigs de Barcelona durant la Guerra Civil, 1936-1939. Barcelona: Publicacions de l'Abadia de Montserrat.

\section{CONTRIBUCIONES DE LOS AUTORES:}

Autor 1: Concepción original del trabajo, redacción y revisión crítica del contenido y aprobación final de la versión a publicar.

Autor 2: Análisis, adquisición y obtención de los datos y aprobación final de la versión a publicar.

Autor 3: Redacción y revisión crítica del contenido y aprobación final de la versión a publicar.

\section{AGRADECIMIENTOS:}

La investigación se ha desarrollado sin ningún soporte económico institucional ni vinculación a ningún proyecto de investigación. 